\title{
Peripartum hysterectomy: two years experience at Nelson Mandela Academic hospital, Mthatha, Eastern Cape South Africa
}

\author{
Wandabwa $\mathrm{JN}^{1}$, Businge $\mathrm{C}^{1}$, Longo-Mbenza B ${ }^{2}$, Mdaka $\mathrm{ML}^{3}$, Kiondo $\mathrm{P}^{4}$ \\ 1. Department of Obstetrics and Gynaecology, Faculty of Health Sciences, Walter Sisulu University, Mthatha, \\ South Africa \\ 2. Faculty of Health Sciences, Walter Sisulu University, Mthatha, South Africa \\ 3. Nelson Mandela academic Hospital, Mthatha, South Africa \\ 4. Department of Obstetrics and Gynaecology, Makerere University, Kampala, Uganda
}

\begin{abstract}
Background: Obstetric haemorrhage is the leading direct cause of maternal mortality in South Africa.

Objective: To determine the incidence, indications, associations and maternal outcomes of emergency peripartum hysterectomies.

Methods: A descriptive and retrospective analysis of patients who had peripartum hysterectomy between $1^{\text {st }}$ February 2007 and $31^{\text {st }}$ January 2009 in Nelson Mandela Academic Hospital at Mthatha city.

Results: The incidence of $0.95 \%$ of peripartum hysterectomies ( $\mathrm{n}=63$ or $9.5 / 1000$ births) increased with the increasing maternal age from $0.121 \%$ at age of less than 20 years to $0.5 \%$ at age more or equal to 30 years. Similarly the incidence increased with parity from $0.332 \%$ for Primiparity to $0.468 \%$ at parity of four or more. The indications for the operation were uterine atony 19/63 (30.2\%), secondary haemorrhage/puerperal sepsis 17/63 (27\%) and ruptured uterus $16 / 63$ (23.4\%). The main intra operative complication was haemorrhage 13/63 (20.6\%). Repeat laparotomy was done in $10 / 63$ $(15 \%)$ of patients due to haemorrhage. Admission to intensive care unit was 25/63 (39.7\%). The case specific mortality rate was of $19 \%(n=12)$. The main causes of death were hypovolaemic shock and septicemia.

Conclusion: The incidence of peripartum hysterectomies was high and was associated with ruptured uterus and puerperal sepsis which are preventable.

Key Words: Peripartum, Hysterectomy, Uterine atony, Ruptured uterus, secondary haemorrhage.

African Health Sciences 2013; 13(2): 469 - 474 http:/ /dx.doi.org/10.4314/ahs.v13i2.38
\end{abstract}

\section{Introduction}

Worldwide the majority of emergency peripartum hysterectomies are carried out in cases of life threatening obstetric hemorrhages. ${ }^{1-3}$ Haemorrhage remains a significant cause of maternal mortality worldwide and even in United Kingdom ${ }^{4}$. In South Africa it's the second leading direct cause of maternal mortality. ${ }^{5}$ Life threatening haemorrhage due to uterine rupture and atony of uterus continue to pose a major problem in obstetric care in developing countries $^{6}$ and is a major cause of peripartum hysterectomies ${ }^{2,3}$. The other indications of peripartum hysterectomy are placenta accreta, increta,

*Corresponding author:
Professor Longo-Mbenza Benjamin
Walter Sisulu University, Faculty of Health
Sciences
Private Bag X1, Mthatha 5117
Eastern Cape, South Africa
Tel+27732822843
Email longombenza@gmail.com

African Health Sciences Vol 13 Issue 2 June 2013 and percreta and, uterine infection ${ }^{1,2,7}$. Peripartum hysterectomy has been used as one of the definitions of near miss events or acute severe maternal morbidity. ${ }^{7,8}$.

The incidence of peripartum hysterectomy varies worldwide with highest rates reported in developing countries. In United Kingdom it is $0.41 /$ 1000 births ${ }^{7}$, Denmark it is $0.24 / 1000$ births $^{9}$, in Saudi Arabia it is $0.64 / 1000^{10}$, in Korle Bu Ghana it is $4.34 / 1000^{2}$, Nigeria $5.4 / 1000^{1}$ and Durban in South Africa 5.1/1000. ${ }^{3}$ The differences have been attributed to the different levels of obstetric care offered.

Several studies have suggested an association of peripartum hysterectomy with previous delivery by caesarean section ${ }^{11-14}$. Currently there is an increase in caesarean section rates worldwide. Reported caesar rates are 23\% in United Kingdom, 29\% in United States of America and up to $50 \%$ in Latin America ${ }^{15}$ and in South Africa ranges between 10 and $50 \%{ }^{16}$. This will have a major public health implication to 
clinicians, the governments and the women in terms of cost, time and effect on health systems because of the increased demand of this procedure.

Peri partum hysterectomies have been reported to be associated with intra operative and post operative complications such as haemorrhage and infection ${ }^{2}$ which lead to severe maternal morbidity and sometimes mortality and yet it is a life saving intervention.

In sub-Saharan Africa including Mthatha in Eastern Cape in South Africa, pregnant women don't easily accept hysterectomy because of socio cultural beliefs of lack of uterus and associated secondary amenorrhea. Peripartum hysterectomy is performed as a life saving measure. The lack of data about the incidence, indications and maternal outcomes in the Eastern Cape gives us a background to initiate a study with view of suggesting ways of preventing and improving maternal outcomes patients who undergo this procedure. The objective of the study was to determine the incidence, indications and maternal outcomes of peripartum hysterectomy.

\section{Methods \\ Design}

This was a descriptive retrospective analysis study where hospital records of consecutive patients who underwent emergency peripartum hysterectomy from $1^{\text {st }}$ February 2007 to $31^{\text {st }}$ January 2009 were reviewed. The study was conducted at Nelson Mandela Academic Hospital, Mthatha South Africa. It is a teaching hospital for Walter Sisulu University and a referral hospital for the Eastern Cape, South Africa. This hospital is a 700 bed hospital. The maternity unit is 54 bed capacity and gets referrals from district hospitals (51.5\%) other hospitals $(29.6 \%)$ clinics $(13.5 \%)$ self referrals $0.5 \%$ and from our clinic $(4.9 \%)$. Mean age of women delivering in this unit was 25.3 and mean parity of 2.4 from annual departmental reports $2010 .{ }^{17}$

The study population included mothers who had come to deliver at the same setting during the study period.

\section{Data collection}

The theatre operation book, the labour ward delivery records and discharge records were reviewed to identify the cases that had ruptured uterus, delivered by laparotomy or had a hysterectomy done. The case notes were reviewed and the required information was extracted and filled in the questionnaire with respect of anonymity and confidentiality according to the Helsinki declaration of human rights.

The hysterectomies were carried out by consultants and senior registrars or senior registrars assisted by consultants. The anaesthesists were medical officers/registrars assisted by specialists. The majority of patients were put on prophylactic antibiotics and those who had obstructed labour, ruptured uterus or puerperal sepsis were put on therapeutic antibiotics depending on the results of culture and sensitivity. The critically ill patients were managed in the intensive care unit (ICU).

Information on complications such as febrile morbidity, defined as a temperature of more than $38^{\circ} \mathrm{C}$ occurring at least two days after surgery and, wound infection defined as presence of purulent discharge and obvious cellulitis with an elevated temperature or positive culture, disseminated intra vascular coagulation, deep vein thrombosis, injury to urinary system and vesico vaginal fistula was searched for.

Information on the socio demographic characteristics, parity, previous obstetric history, mode of delivery, indication for hysterectomy, type of hysterectomy, intra and post operative outcomes and management including intensive care admissions and laboratory results were extracted. Those who died, the causes of death by clinical and postmortem were recorded. The evolution of peripartum hysterectomy was defined by the complications and causes of case fatality.

\section{Statistical analysis}

Data of continuous variable such as age was presented as means standard deviation, while categorical variables were presented as proportions $(\%)$.

Chi square test with $\mathrm{P}$ value for trend (linear association by linear association) was used to compare $\%$ percentages of incidence across the age groups and parity categories. P value of 0.05 was regarded as statistically significant.

EPI INFO computer software version 6.0 for windows and Statistical package for social sciences (SPSS) version 10 for windows (SPSS Inc, Chicago, IL USA were used to compute graphs and statistical comparisons. 


\section{Results}

In the period under the study there were 6628 deliveries. There were 63 cases of peripartum hysterectomy resulting in incidence rate of $0.951 \%$ (9.5/1000 births. Total of $76 \%$ cases underwent subtotal hysterectomies. The mean age of cases that underwent peripartum hysterectomies was $29.6+2$ years and $60 \%$ of cases were below 30 years.
Of the cases who had peripartum hysterectomies, $66.7 \%(n=42)$ had delivered by caesarean section but developed post partum complications and were done hysterectomy.

Table 1 shows the incidence rate of peripartum hysterectomy increased significantly with increasing age.

Table 1: The relationship between peripartum hysterectomy incidence rates and age of study population

\begin{tabular}{lll}
\hline $\begin{array}{c}\text { Increasing age in } \\
\text { years }\end{array}$ & $\begin{array}{c}\text { Number of women } \\
\text { done hysterectomy by } \\
\text { study population }\end{array}$ & $\begin{array}{c}\text { Incidence rate } \\
\text { and P value }\end{array}$ \\
\hline$<20$ & $8 / 3100$ & 0.260 \\
$20-29$ & $22 / 2000$ & 1.100 \\
$\geq 30$ & $33 / 1528$ & 2.160 \\
P for trend & & $<0.0001$ \\
\hline
\end{tabular}

Figure 1 describes the distribution of hysterectomy cases according to age: ages 20-24 and equal or greater than 35 years being the most frequent.

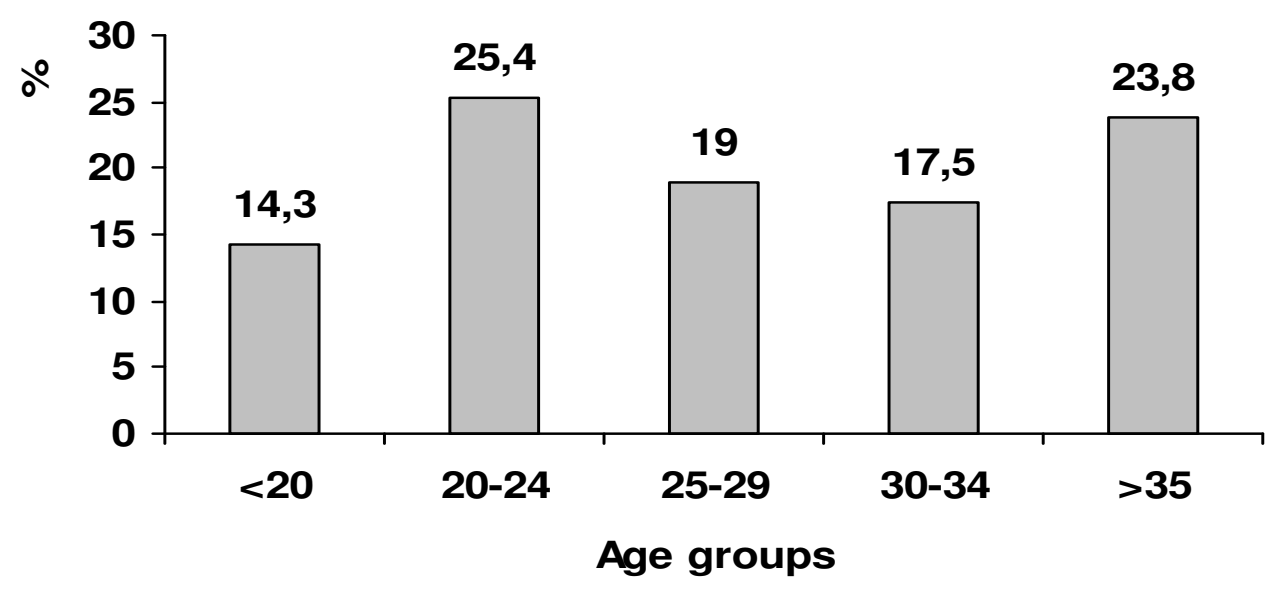

Figure 1: Distribution of participants with hysterectomy according to age groups

The distribution frequency of cases of peripartum hysterectomy by parity category showed a U shaped curve with the highest proportion at grand multiparity, intermediate proportion at Primiparity and the lowest at parity 2. (figure 2). However the linear relationship between peripartumhysterectomy incidence rates and increasing parity was significant ( $\mathrm{P}$ for trend $<0.0001$ ) (table 2 ). The incidence increased from Primiparity to grandmultiparity
Post partum haemorrhage due to atonic uterus $(30.2 \%)$, ruptured uterus, puerperal sepsis and secondary haemorrhage were the most frequent indications for the procedure, while disseminated intravascular coagulation, placenta accreta and cancer of cervix were under represented (table 3). 


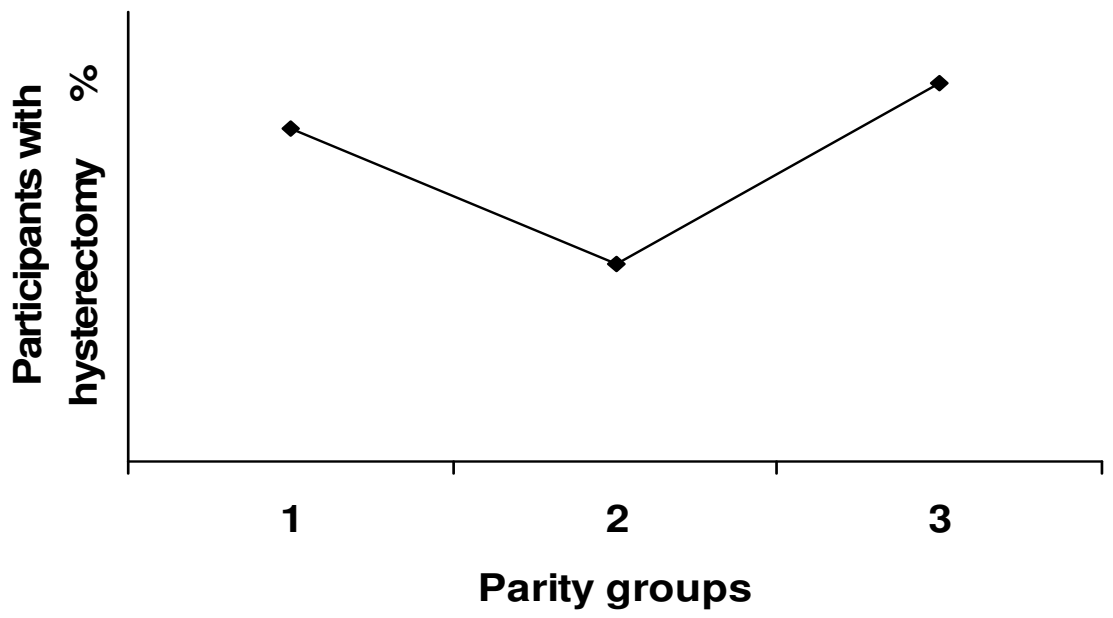

Figure 2: Distribution of participants with hysterectomy according to parity groups.

Table 2: Relationship between peripartum hysterectomy incidence rate and increasing parity of study population

\begin{tabular}{lll}
\hline Increasing parity & $\begin{array}{l}\text { Number of women } \\
\text { done hysterectomy by } \\
\text { study population }\end{array}$ & $\begin{array}{l}\text { Incidence rate } \\
\text { and P value }\end{array}$ \\
\hline $\mathrm{O}-1$ & $22 / 2960$ & 0.740 \\
$2-3$ & $10 / 3150$ & 0.320 \\
$>4$ & $31 / 518$ & 5.980 \\
$\mathrm{P}$ for trend & & $<0.0001$ \\
\hline
\end{tabular}

Table 3: The indications for hysterectomy

\begin{tabular}{lcc}
\hline Indication & Numbers & Percentage \\
\hline Uterine atony & 19 & 30.2 \\
Disseminated intravascular coagulation & 06 & 9.5 \\
Placenta accrete, increta/pacreta & 04 & 6.3 \\
Ruptured uterus & 16 & 23.4 \\
Secondary PPH/Puerperal sepsis & 17 & 27.0 \\
Cancer of cervix & 01 & 1.6 \\
Total & $\mathbf{6 3}$ & $\mathbf{1 0 0}$ \\
\hline
\end{tabular}

Table 4 Summarizes the intra operative and post operative complications of peripartum hysterectomy. Haemorrhage due to disseminated intravascular coagulation was the common complication in the intra operative and post operative hysterectomies. Febrile morbidity and wound sepsis was the main complication post operatively.

Re laparotomy was carried out for persistent haemorrhage and two patients who had ureteric ligation.
In this review the specific maternal mortality rate (case fatality) was $19 \%(n=12)$ The causes of maternal mortality were hypovolaemic shock due to haemorrhage in 4 cases, septic shock four cases and acute renal failure in three normotensive cases and one acute renal failure due to eclampsia. 
Table 4: Intra operative and post operative complications

\begin{tabular}{lcc}
\hline Complication intra operative/ post operative & $\begin{array}{c}\text { Number of } \\
\text { patients }\end{array}$ & Percentage \\
\hline Intra operative haemorrhage due to disseminated & 10 & 15.9 \\
intra vascular coagulation & & 4.8 \\
Intra operative bladder injury & 03 & 15.9 \\
Re laparotomy & 10 & 50.3 \\
Febrile morbidity & 16 & 23.3 \\
Wound sepsis & 7 & 6.7 \\
Vesico vaginal fistula & 02 & 6.7 \\
Post operative haemorrhage & 02 & 10.0 \\
Deep vein thrombosis & 03 & \\
\hline
\end{tabular}

\section{Discussion}

Peripartum hysterectomy is a life saving procedure and was common at Nelson Mandela Academic Hospital (NMAH). In the two years period there were 63 peripartum hysterectomies making the incidence of $9.5 / 1000$ births. This incidence was higher than what has been reported in Durban in South Africa of $5.1 / 1000^{3}$ and in Southern Nigeria of $5.4 / 1000{ }^{1}$ and in Ghana of $4.3 / 1000^{2}$. This incidence was much higher than what has been reported in developed countries which are below 1/1000 births ${ }^{9}, 14$. The difference between NMAH and Durban can be attributed to the differences in the level of obstetric care offered. The difference in incidence between the developed and developing countries can be explained by the level of obstetric care offered in the two regions. This was further explained by the indications for hysterectomies. Better level of obstetric care is associated with lower incidence of peripartum hysterectomies ${ }^{14}$.

Majority $(60 \%)$ of women who had hysterectomies were young aged thirty years and below with the mean age of $29.6 \pm 2$ years. This age was similar to what was described in Durban ${ }^{3}$ and in Ghana ${ }^{2}$. They were young and also of low parity and with mean parity of $2.7 \pm 0.3$ and was similar to what was reported in Ghana ${ }^{2}$ and Nigeria ${ }^{1}$. The study showed an association between increasing age and increasing parity with increasing incidence rate of peripartum hysterectomy. It identified age more than or equal 30 years and parity more or equal to four as risk factors for peripartum hysterectomy and this has been reported in West Africa ${ }^{2,19}$.

The main indications of hysterectomy were uterine atony $(30.2 \%)$, puerperal sepsis $(27 \%)$ and ruptured uterus $(27 \%)$. Similar indications have been reported in Durban and Ghana ${ }^{2,3}$. These were different from that of southern Nigeria where placenta accreta was the main indication ${ }^{1}$. However uterine atony and abnormal placentation remain the main indication of hysterectomies in developed countries $^{9-12,14,18 .}$ The indications for peripartum hysterectomies at NMAH and similarly in Ghana give an insight of level of obstetric care in that puerperal sepsis/ secondary post partum haemorrhage and ruptured uterus contributed $50 \%$ of the indications. These are associated with obstructed labour which is an indication of poor obstetric care. These women laboured in peripheral hospitals and arrived at NMAH with such complications. The HIV status of these patients was not studied. It has been argued that HIV/AIDS may play a role in causation of secondary haemorrhage/ sepsis ${ }^{3}$ but with the use anti retro viral treatment there should be a decrease in this condition.

Majority $(76 \%)$ of patients had subtotal hysterectomies and the rest had total abdominal hysterectomies. Subtotal hysterectomy is routinely used for managing these patients and in a setting where routine screening of cancer of cervix is part of the services provided, its fear is reduced.

The common complication encountered during operation was disseminated intravascular coagulation due to massive transfusion and in addition some of the patients had pre eclampsia and eclampsia. Bladder injury was reported in three patients. Febrile morbidity was the most common post operative complication followed by wound infection. This was common in patients who were done hysterectomy due to sepsis and ruptured uterus. Ten $(15.9 \%)$ patients had re laparotomy done mainly due to persistent haemorrhage. Two patients developed vesico vaginal fistula. This occurred in patients who had puerperal sepsis following obstructed labour and this could have been a result of obstructed labour and not surgery. Similar reports have been reported in Durban and Ghana. ${ }^{2,3}$ 
Out of the 63 women twelve died making the case maternal mortality rate of $19 \%$. This was higher than what has been reported in Ghana of $12.6 \% 2$ and Turkey of $11.6 \%{ }^{18}$ but was lower than what was reported in southern Nigeria of $23.6 \%{ }^{1}$. Some developed countries have reported zero mortality and this is accounted for by better obstetric care. The main causes of deaths were hypovolaemic shock 33.3\% and septicemia 33.3\%. Worldwide massive haemorrhage still remains the major cause of deaths ${ }^{4,5,14}$ and peripartum hysterectomy will remain the main management of refractory haemorrhage.

\section{Conclusion}

Peripartum hysterectomy is high in this part of South Africa and is associated with increasing age, parity, severe maternal morbidity and mortality and an end to woman's reproductive life.

There is need to improve the basic obstetric care services offered in facilities that refer mothers to $\mathrm{NMAH}$ in order to reduce on preventable causes of peripartum hysterectomies such as obstructed labour and ruptured uterus. This includes the use of a partogram to prevent obstructed labour and ruptured uterus and, caesarean section and caesarean hysterectomy when it is needed by the mothers.

\section{References}

1. Umezurike CC, Fevi-Waboso PA, Adisa CA. Peripartum hysterectomy in Aba southern Nigeria. Aust NZJ Obstet Gynaecol 2008; 48(6):580-2.

2. Kwame-Aryee R, A Kwakye A, Seffah JD. Peripartum hysterectomies at Korle-BuTeaching Hospital: A review of 182 consecutive cases. Ghana Med J 2007; 41(3) 133 -138.

3. Sebitloane MH, Moodley J. Emergency peripartum hysterectomy. East Afr Med J 2001; 78(2) $70-4$

4. Confidential Enquiry into Maternal and Child Health. Why Mothers die 2000-2002. London (UK): Royal College of Obstetricians and Gynaecologists; 2004.

5. National Committee on Confidential Enquiries into Maternal Deaths (2012) Saving Mothers: Fifth report on confidential inquiries into maternal deaths in South Africa 2008 - 2010. Pretoria: Government Printer.

6. Plauche WC. Peripartum hysterectomy. Obstet Gynecol Clin Am 1988; 783-95.
7. M. Knight on behalf of UKOSS. Peripartum hysterectomy in UK: Management and outcome of the associated haemorrhage. BJOG 2007;114:1380-7

8. Filippi V. Validation of women's perceptions of near miss obstetric morbidity in South Benin, PhD Thesis 1999, University of London.

9. Sakse A, Weber T, Nickelsen C, Secher NJ. Peripartum hysterectomy in Denmark 19952004. Acta Obstet Gynecol Scand 2007; 86(12): $1472-5$.

10. RahmanJ, Al-Ali M, Qutub HO, Al-Suleiman SS, Al-Jama Fe, Rahman MS. Emergency obstetric hysterectomy in a university hospital: A 25 year review. J Obstet Gynaecol 2008;(1):6972.

11. Sole-Ojeme Do, Bhattacharjee P, Izuwa-Njoku NF, Kadir RA. Emergency peripartum hysterectomy in a tertiary London Hospital Arch Gynecol Obstet 2005, 271: 154-9.

12. Saeed F, Khalid R, Khan A, Masheer S, Rizvi JH. Peripartum hysterectomy: a ten years experience at a tertiary care hospital in a developing country. Trop Doct. 2010 Jan; 40 (1): 18-21.

13. Whiteman MK, Kuklna E, Hills SD, et al incidence and determinants of peripartum hysterectomy. Obstet Gynecol 2006; 108:1486-92.

14. Knight M, Kurinczuk JJ, Brocklehurst P. Caesarean delivery and peripartum hysterectomy. Obstet and gynaecol 2008; 111 (1): 97-105.

15. Vllar J, Valladares E, Wojdyla D, et al. Caesarean delivery rates and pregnancy outcomes: the 2005 global survey on maternal and perinatal health in Latin America. Lancet 2006; 367:1819-29

16. Day C, Barron P, Monticelli F, Sello E, editors. The District Health Barometer 2007/2008. Durban: Health System Trust; June 2009.

17. Department of Obstetrics and Gynaecology, Walter Sisulu University, South Africa: Annual report for2010.

18. Kayabasoglu F, Guzin K, Aydogdu S, Sezginsoy S, Turkgeldi L, Gunduz G. Emergency peripartum hysterectomy in a tertiary Istanbul hospital. Arch gynecol Obstet 2008; 278 (3):2516.

19. Okogbenin GA, Gharoro EP, Otoide VO, Okonta. Obstetric hysterectomy: Fifteen years experience in Nigerian tertiary centre. Journal of Obstetrics and Gynaecology 2003;23:356-359 